\title{
Universalidad y derechos sociales: para una revisión constitucional de las políticas sociales en Argentina
}

\author{
Universality and Social Rights: Toward a Constitutional Revision \\ of Social Policies in Argentina \\ Universalidade e direitos sociais: para uma revisão constitucional \\ das políticas sociais na Argentina
}

HORACIO JAVIER ETCHICHURY*

FECHA DE RECEPCIÓN: 31 DE ENERO DE 2018. FECHA DE APROBACIÓN: 24 DE MAYO DE 2018

DoI: http://dx.doi.org/10.12804/revistas.urosario.edu.co/sociojuridicos/a.6501

Para citar este artículo: Etchichury, H. J. (2019). Universalidad y derechos sociales: para una revisión constitucional de las políticas sociales en Argentina. Estudios Socio-Jurídicos, 21(1), 327-354. Doi: http://dx.doi.org/10.12804/revistas. urosario.edu.co/sociojuridicos/a.6501

\section{RESUMEN}

El texto analiza el alcance de la noción de universalidad en la titularidad de los derechos sociales contenidos en la Constitución argentina. Tras revisar la formulación de esa noción en el texto constitucional argentino, y en los tratados de derechos humanos de igual jerarquía, el texto explora sus consecuencias respecto del diseño de políticas públicas al ponderar las modalidades focalizadas y condicionadas. Se propone revisar las políticas según su compatibilidad con el principio de universalidad.

Palabras clave: universalidad, derechos sociales, políticas públicas.

* Doctor en Derecho y Ciencias Sociales (Universidad Nacional de Córdoba [uncl, Argentina). Master of Laws (Yale Law School, Estados Unidos). Investigador adjunto del Consejo Nacional de Investigaciones Científicas y Técnicas (CONICET). Profesor adjunto de la Facultad de Derecho, UNC. Director de GIDES (Grupo de Investigación en Derechos Sociales). Correo electrónico: etchichury74@gmail.com 


\section{ABSTRACT}

The article analyzes the notion of universality in social rights entitlements under Argentina's Constitution. After reviewing how this notion is phrased in the Constitution and binding human rights treaties endowed with constitutional rank, the article looks into the effects of universality in public policy design, implementation and appraisal. In particular, the article assesses targeted and conditional policies. Finally, the text advocates a policy revision according to consistency with the principle of universality.

Keywords: Universality, social rights, public policies.

\section{RESUMO}

O texto analisa o alcance da noção de universidade na titularidade dos direitos sociais contidos na Constituição argentina. Após revisar a formulação dessa noção no texto constitucional argentino e nos tratados de direitos humanos de igual hierarquia, o texto explora suas consequências respeito ao desenho de políticas públicas, ponderando as modalidades focalizadas e condicionadas. Propõe-se revisar as políticas segundo sua compatibilidade com o princípio de universalidade.

Palavras-chave: universalidade, Direitos sociais, Políticas públicas. 


\section{Introducción}

Mi propósito en este artículo es analizar el alcance de la noción de universalidad en relación con la titularidad de los derechos sociales contenidos en la Constitución argentina. Así se pueden valorar las políticas públicas según su adecuación -en este aspecto- a la ley suprema. El principio de supremacía constitucional obliga a los poderes constituidos a adecuar sus políticas a la Constitución, tanto en su diseño, como en su implementación y su evaluación. Queda, así, abierto el camino para un control de constitucionalidad sobre las políticas públicas.

Luego de revisar la formulación de la universalidad en el texto constitucional argentino, se exploran las consecuencias de esa redacción para el diseño de políticas públicas; en particular, se ponderan las modalidades focalizadas y condicionadas. En una síntesis final, distingo entre las políticas compatibles y las incompatibles con el principio de universalidad tal como lo reconoce el bloque constitucional argentino.

\section{Concepto e impacto en políticas}

En principio, existen dos nociones centrales sobre universalidad (Lema Añón, 2011; Dalli Almiñana, 2017). La primera se refiere a la vigencia o existencia de los derechos humanos (de los sociales, en lo que nos interesa) a través de las culturas y de las épocas, y su discusión se relaciona con la justificación ética y filosófica de los derechos. En general, se cuestiona esta universalidad desde concepciones que ponen énfasis en la diversidad cultural.

Aquí, en cambio, me interesa el segundo sentido de universalidad, el vinculado a la titularidad de los derechos. En este aspecto, la universalidad se refiere al conjunto de personas que resultan titulares de estos derechos si se da por supuesta su aceptación y su consagración en el derecho positivo vigente de una comunidad determinada (local, nacional o internacional).

En principio, la formulación del texto en los tratados de derechos humanos adoptados a partir de 1948 abarca -incluso en los derechos sociales - a "todas las personas". Frente a esta primera lectura se plantean 
objeciones que proponen un menor alcance, por razones éticas, ya sea de carácter económico o político, tal como explica -entre otros- Dalli Almiñana (2015, p. 8). Se alega, por ejemplo, que los derechos sociales no corresponden a todas las personas, sino solo a aquellas que los necesitan o que se hallan en una determinada situación de carencia. La salud o la educación como derechos solo se reconocen a quienes no poseen los recursos financieros para conseguir tales cosas en el mercado. Esto presupone que la adquisición de salud, educación o vivienda se produce naturalmente a través del mercado, y que solo subsidiariamente se obtienen bajo la forma de derechos sociales a través de una prestación del Estado (Lema Añón, 2010, p. 173).

Por lo mismo, sería injusto su reconocimiento generalizado, en especial por tratarse de derechos que implican el uso de recursos públicos. Aquellas personas que, al tener dinero, pueden adquirir por sí mismas la educación o la vivienda, no merecen contar con un derecho a tales cosas; deben obtenerlas a través del mercado y no hacer recaer su bienestar en el tesoro público. Esto da por supuesto que -como se señala más arriba - tales bienes tienen el carácter de mercancía, por lo que el papel de los derechos sociales se limita al de ser un instrumento subsidiario para corregir los problemas más graves de distribución, un derecho "de beneficencia", como críticamente lo denomina Dalli Almiñana (2017, p. 77). Bajo este planteamiento - explica Lema Añón (2010)-, la discusión se centra en el reparto de bienes; no se analiza de ninguna forma la producción, esto es, en la forma social en que la vivienda, la salud o la educación se generan. Esta discusión, precisamente, es necesaria para asegurar la efectiva vigencia de los derechos sociales.

Según el alcance que se reconozca a la noción de universalidad en materia de derechos sociales, el diseño de políticas para su efectiva implementación tendrá un determinado perfil. En principio, si los derechos están en cabeza de todas y cada una de las personas de una comunidad, las políticas públicas deben tener una extensión semejante para llegar a todas ellas. En cambio, una noción más restringida del alcance de los derechos permite adoptar políticas con un alcance menor.

A continuación reviso cuál es la noción de universalidad de derechos sociales presente en el marco constitucional argentino, a fin de determinar qué políticas públicas son compatibles con sus exigencias. 


\section{Concepto en el marco jurídico argentino}

\section{El proceso de incorporación de derechos}

Luego de declarar su independencia, en 1816, Argentina atravesó casi cuatro décadas de guerras civiles e inestabilidad política. La batalla de Caseros, librada en 1852, abre paso a un acuerdo entre las distintas provincias para convocar a un Congreso constituyente, cumpliendo lo previsto en tratados previos. La convención se reúne en 1853 y sanciona una Constitución inspirada, ante todo, en la Constitución estadounidense de 1787. El texto incluye una primera parte destinada a las "declaraciones, derechos y garantías", mientras que la segunda organiza los distintos poderes del Estado en las órbitas federal y provincial. Puede inscribirse, sin demasiado esfuerzo, en el llamado constitucionalismo liberal, o en lo que Abramovich y Courtis denominan el paradigma del derecho clásico. El mercado aparece como el mejor mecanismo de producción y distribución de bienes que, protegido por el Estado, debe dar previsibilidad a las transacciones y repararar las violaciones de derechos (Abramovich \& Courtis, 2002, pp. 50-52). Un conjunto de derechos propios del liberalismo decimonónico se halla en el Artículo 14 (enseñar y aprender, trabajar, navegar, comerciar, publicar ideas por la prensa sin censura previa, etcétera). El derecho de propiedad se presenta especialmente protegido: además de la mención en el Artículo 14, su carácter inviolable se establece en el Artículo 17.

Recién a mediados del siglo Xx se incorporan los derechos sociales concebidos según la tradición impulsada por la Constitución mexicana de 1917. La reforma de 1949 integra los derechos del trabajador, de la familia, de la ancianidad y de la educación y la cultura (Artículo 37). No se incluyen vías judiciales para exigir estos derechos ${ }^{1}$.

Escribiendo poco tiempo después de esa reforma, Antoni (1950, pp. 24-51) señala que la verdadera garantía de los derechos sociales se halla en el modelo económico adoptado en la ley suprema. En efecto, el texto establece una política económica intervencionista y nacionalista que modifica el marco ideológico liberal sostenido desde el siglo XIX. Los artículos 38 (función social de la propiedad), 39 (subordinación del capital al bienestar social) y 40 (propiedad estatal de las fuentes de energía, los yacimientos y los servicios públicos) definen ese nuevo paradigma económico. 
La dictadura militar, surgida del golpe de Estado de 1955, deroga esos cambios, restaura el texto liberal de $1853 \mathrm{y}$-sin respetar el procedimiento constitucional - convoca a un nuevo proceso de reforma para dar cabida a los derechos sociales bajo una redacción diferente (Sagüés, 1999, I, p. 219; Quiroga Lavié, 2000, p. 82). La Convención reformadora de 1957 incorpora así el Artículo 14 bis., vigente hasta hoy. Ese artículo consagra los derechos de las personas que trabajan y de los gremios, además de regular la seguridad social.

Por último, la reforma de 1994 expande el elenco de derechos (Dalla Via, 2006, pp. 125-126) mediante el otorgamiento de jerarquía constitucional, "en las condiciones de su vigencia"2, a un conjunto de tratados internacionales de derechos humanos (CN, Artículo 75, inciso 22), incluyendo la Declaración Universal de Derechos Humanos (DUDH), el Pacto de Derechos Civiles y Políticos (PDCP), el Pacto de Derechos Económicos, Sociales y Culturales (PDESC), la Convención para la Eliminación de todas las formas de Discriminación contra la Mujer (CEDM) y la Convención de los Derechos del Niño (CDN). Por otra parte, se habilita un mecanismo para dar la misma jerarquía a otros tratados a través de mayorías agravadas en el Congreso. Así, por ejemplo, hace poco (diciembre de 2014) se otorgó -mediante la Ley 20.744- rango constitucional a la Convención sobre los Derechos de Personas con Discapacidad (CDPD).

Todos estos instrumentos consagran, no solo derechos laborales, sino también el derecho a la salud, a un nivel de vida adecuado, a la vivienda, a la alimentación, al vestido, a la educación, a la participación en la vida cultural y a beneficiarse del progreso científico, entre otros. Por otra parte, la misma reforma estableció el principio de la igualdad real de oportunidades y de trato (Artículo 75, inc 23), que vino a completar la igualdad formal ante la ley, consagrada desde 1853 en el Artículo 16 de la CN (Rossetti E Álvarez, 2010). 
En el PDESC, al igual que en la DUDH, se adopta una fórmula de carácter universal para el reconocimiento de derechos: "toda persona". Lo mismo ocurre con los demás tratados. Aquí se percibe con claridad la diferencia con otras constituciones que consagran derechos con alcance menor. Por ejemplo, la Constitución española de 1978 reconoce a "todos" el derecho a la vida (Artículo 15), a la educación (Artículo 27) o a sindicarse libremente (Articulo 28) pero solamente a "todos los españoles" el derecho a peticionar (Artículo 29), al trabajo (Artículo 35) o a la vivienda (Artículo 47). Ello traza una frontera visible entre las personas -dentro de un mismo espacio geográfico- según la posesión o carencia de un determinado estado de nacionalidad o ciudadanía.

En el caso de las CEDM, la CDN y la CDPD el reconocimiento de derechos se hace a todas las personas que integran el grupo definido por el instrumento. En el caso del PDESC, el alcance universal se halla reforzado por el Artículo 2.2 que prohíbe discriminar "por motivos de raza, color, sexo, idioma, religión, opinión política o de otra índole, origen nacional o social, posición económica, nacimiento o cualquier otra condición social". Este principio específico de no discriminación se suma al citado Artículo 16 de la Constitución, que declara la igualdad de todos los habitantes ante la ley.

3 En general, la noción de "universalidad" no ha merecido un tratamiento extensivo o detenido en textos muy difundidos de la doctrina constitucional argentina, tales como Rosatti (2010) o Dalla Via (2004), o incluso en obras colectivas sobre temática de derechos como Clérico et al. (2013) o Rivera et al. (2014). Lo usual es simplemente consignar que el Artículo 14 reconoce derechos a "todos los habitantes" en correlación con la cláusula de igualdad formal en el citado Artículo 16, pero sin desarrollar sus proyecciones. Así puede leerse, por ejemplo, en autores de gran circulación como Bidart Campos (2000, pp. 754, 762, 770), Sagüés (1999, II, pp. 302-304) o Gelli (2005, p. 75). No se acostumbra poner esos preceptos en relación con los textos pertinentes de los tratados de derechos humanos dotados de jerarquía constitucional, con el fin de delinear mejor el alcance de los derechos consagrados. Hay, a veces, alusiones a la "universalidad" como principio propio del derecho internacional de los derechos humanos, pero sin extraer consecuencias para el orden jurídico interno. No hay -en las obras de mayor circulación- una discusión más profunda del concepto, tal como la que ofrece - entre otros- un autor español como Lema Añón (2009, pp. 170-200). 


\section{La situación de las personas extranjeras}

Sin embargo, el PDESC incluye una limitación: su Artículo 2.3 permite a "los países en desarrollo" establecer una protección diferenciada de los derechos. Esos Estados "teniendo debidamente en cuenta los derechos humanos y su economía nacional, podrán determinar en qué medida garantizarán los derechos económicos reconocidos en el presente Pacto a personas que no sean nacionales suyos". Se abre la posibilidad de delimitar un alcance, de ciertos derechos, menor al de "todas las personas" sujetas a la jurisdicción de esos Estados. Al menos algunos derechos (la categoría de "económicos" necesitaría una aclaración fundada para distinguirlos de los "sociales" y "culturales") podrían tener esa tutela reducida, ya que las personas extranjeras podrían no ser titulares de ellos, o serlo en menor medida.

¿Es aplicable esta limitación en el caso argentino? Para ello, sería necesario determinar qué se entiende por "país en desarrollo" y qué indicadores o propiedades podrían utilizarse para dar contenido a ese concepto. En principio, es razonable pensar que el Pacto incluye solo dos categorías: "países en desarrollo" y, de modo implícito en el texto, "países desarrollados". Si esto es así, Argentina podría ser incluida, más allá de sus indicadores económicos, sociales y culturales, en la primera categoría.

Solo para los fines de la presente argumentación, daré por sentado que el Artículo 2.3 del Pacto hace referencia a Argentina, incluyéndola en la categoría implícita de "país desarrollado". Aun en tal caso, el orden jurídico argentino no permite negar protección u ofrecer una protección reducida a los derechos del Pacto para el caso de las personas que no son nacionales del país. En efecto, el Pacto solo puede interpretarse de modo integrado con el resto del texto constitucional, con el que comparte la jerarquía normativa máxima. En este punto cobran relevancia cláusulas de la primera parte de la Constitución.

En primer lugar, el texto de los Artículos 14, 14 bis y 33 dejan establecida la amplísima extensión de los derechos constitucionales. Por una parte, el Artículo 14 garantiza los derechos enumerados a "It]odos los habitantes de la Nación", esto es, a cualquier persona que viva en el país, sin distinción de nacionalidad. Si bien el Artículo 14 no incluye los derechos sociales, el 14 bis (incorporado en 1957) establece los derechos del 
trabajador sin hacer ninguna diferencia entre argentinos y extranjeros. Por último, el Artículo 33 (incluido en la reforma de 1860) garantiza la misma protección a los derechos "no enumerados", entre los que, sin dificultad, se incluyen los ahora reflejados en los diversos pactos internacionales.

Existe una importante norma adicional y específica que aclara el lugar de los extranjeros en el orden jurídico argentino. Se trata del Artículo 20 que integra la Constitución desde 1853 y establece que "[l]os extranjeros gozan en el territorio de la Nación de todos los derechos civiles del ciudadano". Esta equiparación entre nacionales y no nacionales en el goce de derechos (Gelli, 2005, p. 286) puede tomarse como clave definitiva para excluir la aplicación del Artículo 2.3 del Pacto. Sin embargo, la referencia a derechos "civiles" puede confundir. En principio, sirve para marcar la diferencia con derechos "políticos", en los que sí se admite la diferencia basada en la nacionalidad (así, una persona extranjera puede tener limitaciones en sus derechos a votar o a ser elegida para una función pública). Sin embargo, el artículo aporta una enumeración de derechos que se reconocen de modo igualitario a quienes no tienen nacionalidad argentina: "ejercer su industria, comercio y profesión; poseer bienes raíces, comprarlos y enajenarlos; navegar los ríos y costas; ejercer libremente su culto; testar y casarse conforme a las leyes". Es decir, se incluyen a derechos de corte "económico", lo cual amplía el sentido de la expresión "derechos civiles", única disponible en 1853 para aludir a derechos no políticos. Por lo tanto, una lectura integrada del reconocimiento de derechos a los "habitantes" del país (Artículo 14), la enumeración de derechos del trabajador sin distinciones de nacionalidad (Artículo 14 bis), junto a la protección igualitaria de derechos "no enumerados" (Artículo 33) y el expreso compromiso de reconocer derechos, incluso de contenido económico a los extranjeros (Artículo 20), resultan en una pauta constitucional de equiparación entre extranjeros y argentinos en el goce de los derechos (con exclusión de los derechos políticos).

De esta forma, la Constitución impide hacer uso de la prerrogativa concedida a los "países en desarrollo" por el Artículo 2.3 del PDESC. Argentina, en artículos que tienen igual jerarquía a la del Pacto, ha definido la igualdad en el goce de derechos para personas "que no sean nacionales" del país. 
En síntesis, el marco constitucional argentino reconoce los derechos sociales explícitos en su Artículo 14 bis y en el articulado aplicable de los pactos de derechos humanos, así como también los eventuales derechos sociales no enumerados (Artículo 33), con un alcance "universal" entendido como extendido a "todos los habitantes" del país, o bien a "todas las personas", sin hacer distinción en razón de la nacionalidad, ni por ningún otro motivo (PDESC, Artículo 2.2; Artículo 16 de la CN).

\section{El impacto en el marco argentino}

Una vez definido el alcance (en cuanto a sus titulares) de los derechos sociales en el orden constitucional de Argentina, se debe explorar su proyección en el diseño de políticas sociales.

\section{El rango de los derechos y el sistema federal}

En virtud del principio de supremacía constitucional, contenido en el Artículo 31 de la CN, toda política pública (e incluso la inacción pública) debe guardar coherencia con los derechos reconocidos en la Constitución (Gelli, 2005, p. 366). Las políticas públicas -incluyendo las sociales- se pueden definir como tomas de posición y cursos de acción del Estado (o de sus representantes), frente a una cuestión que la sociedad considera un problema, con el objetivo de resolverlo, aunque no sean soluciones de fondo (Oszlak, 2009, p. 2). En ese sentido, toda política pública está compuesta por distintas normativas y acciones; todas ellas pueden evaluarse según su compatibilidad con el marco constitucional. La norma de máxima jerarquía fija obligaciones de conducta (qué medios puede y debe utilizar, así como también cuáles no están admitidos) y de resultado (Sepúlveda, 2014, p. 13), lo que define un espectro -más o menos amplio-de políticas constitucionalmente admisibles. A ello debe sumarse que en el orden jurídico argentino vigente existen distintas vías para impugnar judicialmente la constitucionalidad de acciones $u$ omisiones estatales, tales como la acción de amparo prevista en el Artículo 43 por reclamos individuales o colectivos (Jiménez, 2015). 
Por lo tanto, las políticas (en tanto conjunto de acciones estatales) en materia educativa, social, sanitaria, alimentaria, urbana (o de cualquier otra índole, en suma) no deben diseñarse teniendo en cuenta tan solo objetivos políticos o condiciones económicas, sino también las exigencias que los derechos imponen al Estado argentino, con el fin de prevenir su impugnación judicial sobre bases constitucionales.

El principio de universalidad de los derechos, por su rango constitucional, obliga al Estado a que sus políticas en las diversas áreas aseguren el efectivo goce de los derechos por parte de "todas las personas" o de "todos los habitantes". De los diferentes modelos creados para la acción estatal a lo largo de la historia, el Estado argentino debe elegir solo aquellos que resulten coherentes con los compromisos adoptados por Argentina hacia su propia población y hacia la comunidad internacional.

A primera vista, las políticas que cumplen con el principio de universalidad son, precisamente, las de carácter universalista. Ello exige no solo una cobertura universal, sino una asignación transparente de los derechos reconocidos, de servicios de calidad y un financiamiento equitativo, además de sustentable (Filgueira, 2014, pp. 49-50). Un ejemplo muy conocido es el denominado "modelo Beveridge", en alusión al informe presentado en 1942 al Parlamento inglés que aconsejaba la creación del National Health Service, ejemplo de política universal y no contributiva de salud (Lema Añón, 2012, p. 31). Otros posibles ejemplos son la creación de sistemas educativos o sanitarios públicos y gratuitos para toda la población, el pago de una renta básica a toda persona, el otorgamiento de pensiones o jubilaciones a cada individuo.

En el caso argentino, esta dimensión de universalidad debe cruzarse con la forma de Estado federal. El PDESC (Artículo 28) establece claramente que cada unidad subnacional (las provincias en este caso) tiene obligación de satisfacer los derechos consagrados en el Pacto. Esto lo hace, por supuesto, dentro de las facultades no delegadas al Gobierno Federal (Hernández, 2009, p. 332). Por ejemplo, las provincias argentinas han implementado sus propios sistemas educativos o de salud. La universalidad puede alcanzarse también de esta forma: cada provincia se encarga de asegurar el goce de los derechos a quienes habitan sus territorios. El Estado nacional, por su parte, funciona como garante efectivo 
de la universalidad; no puede excusarse al alegar que las provincias han asumido la prestación relativa a un derecho ${ }^{4}$.

Tanto en el plano internacional como en relación al derecho interno, el compromiso del Estado nacional abarca todos los derechos contenidos en el PDESC. El Estado federal puede elegir la forma de cumplir ese cometido. Puede establecer sistemas complementarios para garantizar un derecho, así, por ejemplo, durante varias décadas existieron escuelas primarias nacionales que cubrían las áreas donde las provincias no lograban construir establecimientos. Una segunda forma en que el Estado federal puede cumplir su papel es al crear el sistema principal para la satisfacción de un derecho, con la posibilidad de que las provincias adhieran a él y contribuyan a sostenerlo, o bien creen y mantengan sistemas accesorios. Un modelo puede hallarse en las universidades públicas nacionales que representan el mecanismo para garantizar el derecho a la educación superior (PDESC, Artículo 13). En ese marco, las universidades provinciales juegan un papel accesorio. Del mismo modo, el sistema previsional hoy representa el instrumento central para dar vigencia al derecho a la seguridad social (PDESC, Artículo 9; CN, Artículo 14 bis); en esta área, algunas provincias mantienen cajas para su personal.

\section{La universalidad formal y en los hechos: grupos protegidos}

Mediante cualquiera de estas modalidades, el Estado argentino asegura la vigencia efectivamente universal de los derechos sociales. Sin embargo, es necesario prestar atención a una crítica recurrente a las políticas universales. En algunos casos se ha señalado que, en los países en desarrollo, los enfoques llamados universales han conducido a un "universalismo estratificado" o "falso" debido a que la fuerza de trabajo no está formalizada por completo. De esa forma, la cobertura universal es solo aparente porque un amplio sector (tal como el de trabajadores informales o el de las mujeres) no queda incluido (Leubolt, Fischer $\mathcal{E}$ 
Saha, 2014, pp. 76, 89). Por ello, hoy estas políticas no son suficientes desde el punto de vista constitucional.

Existen entonces ciertos grupos que, pese a la promesa formal de universalidad de los derechos, siguen sin poder ejercerlos. A ellos la Constitución les reconoce una protección especial y, por ello, las políticas universales deben complementarse con otras destinadas a asegurar la vigencia de los derechos en esos colectivos. En general, esa calidad deriva de tratados internacionales con jerarquía constitucional: las mujeres (CEDM), las personas menores de 18 años (CDN) y las personas con discapacidad (CDPD). El Artículo 14 bis, por otra parte, establece que "el trabajo, en sus diversas formas, gozará de la protección de las leyes", lo cual fija una situación constitucional diferenciada favorable a las personas que trabajan. Las personas ancianas también han sido definidas por la Constitución como merecedoras de "acciones positivas", esto es, adicionales a las políticas que se aplican de modo general. Los "pueblos indígenas argentinos" (CN, Artículo 75, inciso 17) también se destacan como un grupo al que se le reconoce una condición especial: su "preexistencia étnica y cultural" respecto del Estado argentino les confiere derechos particulares, tanto en lo grupal (la propiedad comunitaria de tierras que tradicionalmente ocupan) como en lo individual (derecho a una educación bilingüe e intercultural); tales derechos exigen políticas adicionales.

Por lo tanto, la "universalidad", genuinamente entendida a partir del marco constitucional argentino, exige la satisfacción de los derechos de todas las personas mediante políticas de alcance universal, implementadas por la Nación o las provincias (aunque la Nación siempre es garante), complementadas con las acciones positivas que requiera la protección de los grupos especialmente definidos.

\section{Políticas no universales}

Sin embargo, no todas las políticas sociales diseñadas e implementadas por el Estado argentino tienen carácter universal. Muchas pueden definirse como "focalizadas", esto es, destinadas a sectores específicos dentro de la población, sin que se trate de los grupos reconocidos como especialmente protegidos. Así, por ejemplo, el Plan Jefes y Jefas de Hogar, 
adoptado en 2002 (Decreto 565/2002), se dirigía a un colectivo social definido con precisión en el Artículo 2 del Decreto 5 .

Otras políticas pueden tener un alcance más o menos amplio, pero estrechan su cobertura mediante la exigencia de "condiciones" para acceder a la prestación que satisface un derecho. Es el caso de las llamadas "transferencias monetarias condicionadas" (TMC) (Fiszbein et al., 2009).

En otros casos, el discurso político pone énfasis en la definición de "prioridades" en las políticas públicas (Peña Freire, 2017, p. 259), incluso en las sociales (Sunstein, 2004, pp. 145, 212). Esto exige seleccionar segmentos de población que quedarán excluidos del goce de ciertos derechos.

En principio, estos tres tipos de políticas aparecen como contrarios al principio de universalidad. Elegir un grupo (o un derecho) para concentrar allí los recursos y la acción del Estado, mientras se desatiende al resto, significa que no "todas las personas" verán garantizado su derecho (o todos los derechos). Quizás una persona pueda gozar de, digamos, salud sin necesidad de la asistencia estatal, pero la focalización significa que no tiene una garantía (entendida como exigibilidad) para disfrutar de ese derecho. Si las circunstancias cambian y se enferma, solo tendrá salud si queda incluida en el grupo "focal" determinado en la política. El Estado define quién goza del derecho y quién no: es exactamente lo contrario de lo que significa darle jerarquía constitucional al PDESC. Hace poco, la noción de "universalidad" fue reformulada para abarcar casos que -implícitamente- pueden incluir estrategias de focalización. Así puede verse en la publicación del Banco Mundial (2015) titulada Going universal. How 24 developing countries are implementing Universal Health Coverage reforms from the bottom up. Ese texto analiza las vías y posibilidades para alcanzar la cobertura universal en salud, pero la define de esta forma: "que todas las personas tengan acceso a los cuidados de salud que necesiten sin sufrir dificultades financieras" (Banco Mundial, 2015, p. 21; énfasis añadido). De modo que la "universalidad" en este esquema abarca - en rigor- a las personas que podrían atravesar problemas financieros para tratar sus enfermedades. Quienes puedan recibir cuidados sin afectar demasiado su 
presupuesto personal o familiar, no son relevantes para la universalidad así definida: seguirán proveyéndose, por sus propios medios, la atención médica. El Estado reserva sus recursos solo para quienes están en situación económica desfavorable o riesgosa: ahí está el "foco". Para comprender con claridad la implicancia de este planteamiento, basta pensar si resultaría aceptable definir "educación primaria universal" como un sistema que asegurara escuela pública solo a quienes no puedan pagar otra.

Por otra parte, también se critica la focalización por los frecuentes errores de inclusión y exclusión, los procesos costosos de empadronamiento, o el fomento de relaciones clientelares (Leubolt, Fischer \& Saha, 2014, p. 89). Al analizar el caso estadounidense de comienzos de los años noventa, Skocpol sostiene que los programas focalizados contra la pobreza, iniciados en la década de los sesenta, han tenido financiación insuficiente y falta de sustentabilidad política (por el rechazo de quienes deben pagar más impuestos para solventar estos programas), además de un efecto degradante (Skocpol, 1991, pp. 29-33). Como ya se señaló, estas políticas presuponen el carácter "natural" de la salud o de la educación como mercancías. Por otra parte, la selección de "focos" conlleva un efecto estigmatizante (Young, 2014, p. 97; Lema Añón, 2010): quedar incluido en uno de los "focos" significa que su titular fracasó en el intento de conseguir los recursos necesarios para comprar en el mercado las prestaciones en juego. En cambio, el acceso universal es la estructura más simple, más transparente e incluso más económica, además de que previene la estigmatización de los grupos incluidos; por ello la focalización debe ser solo un instrumento analizado "con mucha cautela" (Sepúlveda, 2014, p. 24). La adopción de políticas universales se sostiene en argumentos de eficiencia social y de ética (Lessa Kerstenetzky, 2006, pp. 571-572), ya que se eliminan los costos derivados de un diseño y de un control minuciosos, así como los citados efectos de la estigmatización. En perspectiva ética, la universalidad de los derechos "desmercantiliza" (Esping-Andersen, 1993) determinados bienes, y ello conduce a una comunidad de iguales donde las necesidades de numerosos bienes y servicios se satisfacen por mecanismos de distribución que no son el mercado, sino las decisiones adoptadas a través de un procedimiento democrático, como el que se aplica a la creación de impuestos, a la asignación de fondos 
presupuestarios o a la designación de elencos administradores para las diferentes áreas estatales.

\section{La admisibilidad de políticas no universales}

Sin embargo, es posible justificar políticas focalizadas, condicionadas o prioritarias, aunque sea como excepción al principio general (universalidad). En tales casos, este tipo de programas pueden ser compatibles con la Constitución y con los tratados de igual jerarquía. Los fundamentos para ello no coinciden, en general, con los argumentos sostenidos tradicionalmente por los órganos políticos para su adopción. Las políticas no universales suelen defenderse o presentarse bajo argumentos de ahorro fiscal, mejoramiento moral de la población pobre, o bien, fomento de las inversiones extranjeras. Ninguno de esos criterios tiene fuerza justificatoria bajo un paradigma de derechos humanos. Aquí revisaré, entonces, las razones que sí resultan aceptables en este marco.

\section{Combinación de políticas no universales}

En primer lugar, las políticas focalizadas pueden resultar justificadas si, tomadas en conjunto, cubren a la totalidad de la población. Quizá sea poco frecuente encontrar estas situaciones. Es posible, sin embargo, que en un Estado federal, como el argentino, determinados derechos sean atendidos por las provincias, lo que podría dar origen a tantos sistemas educativos o sanitarios, como unidades subnacionales existan. También es posible que el Estado nacional, por razones históricas, haya creado paulatinamente sistemas previsionales parciales, destinados a diferentes grupos y que, de esa forma, haya logrado una cobertura universal. Razones de eficiencia probablemente aconsejen unificar los subsistemas en uno más amplio, pero la coexistencia de programas parciales no resulta, por sí misma, contraria a la universalidad siempre y cuando no haya personas excluidas, ni desigualdades injustificables entre los niveles de efectiva vigencia de los derechos en las diferentes unidades jurisdiccionales. La brecha entre los sistemas previsionales provinciales y el de la Nación, ha sido señalada con frecuencia como una dificultad para alcanzar el goce universal del derecho a la seguridad social, dadas las disparidades de 
género, de prestaciones y de requisitos y de alcance de las coberturas (Bestard, Carrasco y Pautassi, 2015).

\section{Implementación progresiva de la universalidad}

En segundo término, el principio de progresividad (consagrado en el Artículo 2.2 del PDESC) también hace admisibles políticas no universales. Dado que puede resultar imposible la concreción inmediata del goce efectivo de todos los derechos sociales para todas las personas, el Pacto habilita la consecución paulatina de ese nivel generalizado de cumplimiento: cada Estado "se compromete a adoptar medidas [...] para lograr progresivamente, por todos los medios apropiados, inclusive en particular la adopción de medidas legislativas, la plena efectividad de los derechos aquí reconocidos". Así, Argentina debe mejorar continuamente el nivel de goce de los derechos, avanzando en su implementación, incrementando

poco a poco la extensión y cobertura (Courtis, 2006, pp. 21-22). A la vez, no puede recortar los logros ya alcanzados: este es el principio de "no regresividad" que impide los retrocesos (Sepúlveda, 2006, p. 124). Si se analiza un momento determinado de la historia de un país, la existencia de políticas no universales puede resultar aceptable bajo un marco de derechos humanos, siempre y cuando ese planteamiento no universal represente una etapa en un progreso sostenido y reconocible.

\section{Las acciones positivas}

Un tercer caso de política focalizada o prioritaria justificada se halla, como se anticipó, en los programas destinados a brindar asistencia o recursos adicionales a grupos señalados en la Constitución como especialmente protegidos. Se trata de las llamadas "acciones positivas" (así denominadas en el Artículo 75, inciso 23 de la CN). Un ejemplo podría hallarse en la creación de becas para alumnas o para estudiantes con discapacidad en el marco de un sistema educativo universal gratuito. De esta forma, además del acceso sin cargo, quienes reciban las becas tendrían un elemento más para garantizar que puedan ejercer su derecho a educarse. Puede imaginarse otro ejemplo: la formación de un cuerpo de médicos domiciliarios para personas ancianas dentro de un sistema de 
salud universal y gratuito. En casos como estos, se entiende la focalización, en rigor, como una "acción reparatoria" (Lessa Kerstenetzky, 2006, pp. 568-571); tal acción es necesaria para asegurar "a ciertos grupos sociales el acceso efectivo a derechos universales formalmente iguales" (énfasis en el original) a través de medidas complementarias. Puede darse a través de políticas redistributivas compensatorias a nivel individual, grupal o estructural.

Es necesaria una aclaración importante. Las "acciones positivas" siempre tienen carácter adicional, esto es, presuponen la existencia de sistemas y políticas destinadas a toda la población para hacer efectivo ese mismo derecho. No otorgan un permiso al Estado para desentenderse de la comunidad y concentrarse solo en el grupo específico. Volviendo a los ejemplos anteriores: si "todas las personas" tienen derecho a la salud, el cuerpo de médicos domiciliarios para personas ancianas no habilita al Gobierno a reducir o eliminar la atención sanitaria al resto de la población en sus hospitales. Como tampoco la implementación de becas para alumnas permite descuidar el estado de las escuelas donde asisten estudiantes varones y estudiantes mujeres. La aclaración es relevante porque la focalización, en general, es presentada como un sustituto de políticas universales. Para ser compatible con la Constitución, en cambio, debe ser complementaria de ellas.

Situación de las políticas condicionadas: la razonabilidad como criterio

En este tipo de políticas, las prestaciones destinadas a satisfacer un derecho se subordinan al cumplimiento de ciertas conductas o requisitos. Las TMC representan la modalidad más difundida en los últimos años. El Estado entrega una suma de dinero a una persona para asegurar los derechos a la salud, a la educación y a la alimentación de sus hijos, siempre y cuando esa persona presente - por ejemplo-constancias de escolaridad y de vacunación de esos niños.

A primera vista, la política parece no ser universal: no abarca a "todas las personas", sino solo a aquellas que presentan certificados; quienes no lo hagan, quedan fuera de ese programa. Sin embargo, es posible justificar, en ciertos casos, estas condiciones bajo el marco constitucional argentino. 
Para ello, las condiciones deben analizarse como reglamentaciones del derecho en juego.

En tanto regulación de un derecho, las condiciones (presentación de constancias escolares o certificados de vacunación) deben cumplir con el requisito de razonabilidad, establecido en el Artículo 28 de la $\mathrm{CN}$. La reglamentación no puede alterar el derecho en cuestión, no puede limitarlo desproporcionadamente con el supuesto objetivo de asegurar su goce simultáneo y ordenado por todas las personas. La Corte ha sostenido, en reiteradas ocasiones, que este principio exige que haya una relación proporcional entre los medios elegidos y los propósitos perseguidos (Gelli, 2005, p. 331; Bidart Campos, 1991, p. 407), y una relación causal entre esa limitación de derechos y el objetivo buscado, tal como el Alto Tribunal señaló en "Irízar" (1996)6. Una política debe utilizar medios que sirvan para alcanzar fines legítimos sin que resulten en cargas desproporcionadas sobre la población. Si resultan razonables, las condiciones pueden ser aceptadas como una reglamentación admisible del derecho, cuyo alcance universal sigue en pie.

Analizo aquí un ejemplo importante en el derecho argentino actual. La AUH (creada por Decreto de Necesidad y Urgencia 1602/2009) consiste en un pago mensual por cada hijo o hija menor de 18 años, hasta un máximo de cinco hijos por familia. Se entrega a cada madre o padre que esté sin empleo, o que tenga un trabajo en el sector informal, siempre y cuando no gane una cifra superior al salario mínimo, vital y móvil. La AUH se presenta como la extensión al conjunto de trabajadores desocupados o informales de las Asignaciones Familiares (AF) pagadas al personal registrado. El decreto establece, como condición para recibir el monto transferido completo y para continuar en el programa, la presentación de certificados de escolaridad, de vacunación y de ciertos controles médicos (Straschnoy, 2016, p. 184). Los derechos principales en juego son los derechos a la salud, a la educación y a la alimentación de los niños y las niñas. En ese sentido, la entrega del dinero a sus padres tiene un papel instrumental. El Estado adopta estas condiciones como una forma de asegurarse que se alcance la efectiva vigencia del derecho

6 "Irízar, José M. c/ Provincia de Misiones". Fallos, 319: 1934. 12 de septiembre de 1996. 
a la educación (mediante la presentación de una constancia de asistencia a la escuela), del derecho a la salud (constatado en el certificado de vacunas) o del derecho a la alimentación (verificado en los exámenes clínicos). Esta reglamentación impone una carga sobre el derecho de los padres a administrar el dinero transferido por el Estado, pero -aunque merezca un análisis más detallado, lo cual no es el objetivo de este trabajo- puede considerarse en principio como una carga proporcional al fin legítimo buscado. Si el fin fuera diferente, quizá la relación de proporcionalidad no se sostenga y la reglamentación pueda resultar irrazonable. Ese sería el caso si las condiciones se fijaran con el objetivo de volver más aceptable, políticamente, la AUH para quienes no integran el grupo beneficiario (digamos, al afirmar que "se entrega dinero, pero se exige algo a cambio"). Dicha finalidad, puramente electoral o política, podría resultar insuficiente para justificar las limitaciones y cargas impuestas como reglamentación. Del mismo modo, la razonabilidad debe analizarse a la luz de las consecuencias del incumplimiento de los requisitos (cuando el efecto es la pérdida completa del beneficio, quizá se está dejando de lado el fin legítimo de asegurar los derechos de los niños y las niñas).

Caben algunas consideraciones más. Las condiciones deben respetar el principio de igualdad (previsto en el Artículo 16 de la $\mathrm{CN}$ ). No pueden exigirse condiciones a un grupo de padres y a otro no; ello requiere, también aquí, una justificación razonable desde el punto de vista del Artículo 28. En el caso de la AUH, existe un trato diferente entre trabajadores formales e informales. El primer grupo recibe el pago de las AF sin necesidad de presentar ninguna de las constancias que los trabajadores informales deben entregar a fin de percibir la AUH. Dado que ambas asignaciones tienen el mismo monto y las mismas finalidades, resulta injustificada -al menos en principio- el trato desigual, basado en una circunstancia que no depende de la voluntad de las personas (la formalidad en el empleo).

A la vez, las condiciones no pueden referirse a la vida privada. No habilitan lo que Nino llama "perfeccionismo", esto es, el intento del Estado de imponer ciertos ideales de conducta o de vida cuya definición pertenece a las personas (Nino, 1992, p. 166). Straschnoy (2016, p. 188) señala que, en las declaraciones de las autoridades, las condiciones aparecen como una vía para incidir en la conducta de las personas con el objetivo de corregir instancias previas de socialización. 
El derecho a la privacidad y a la autonomía personal (CN, Artículo 19) pone a salvo de toda interferencia estatal las decisiones sobre el propio plan de vida. Por lo tanto, el Estado no podría, por ejemplo, condicionar el acceso a una política social a la adopción de una creencia religiosa, a la formalización de determinados arreglos familiares, o a la participación en determinadas actividades sociales, culturales o políticas. Todo ello forma parte de la amplia área vital excluida de "la autoridad de los magistrados", según el texto constitucional adoptado en 1853. La tentación estatal de "mejorar" a las personas por medio de la fijación de condiciones para percibir dinero amenaza la autonomía personal.

Podemos citar un ejemplo más reciente. A fines de diciembre de 2017, el Congreso argentino aprobó una nueva distinción en materia de derechos sociales. Mediante la Ley 27.426, denominada de "Reforma Previsional"7 ${ }^{\prime}$, estableció que quienes acreditaran treinta años o más de contribuciones al sistema jubilatorio tendrían garantizado un ingreso mínimo equivalente al 82 \% del salario mínimo, vital y móvil del personal en actividad (Articulo 5). Esta garantía no protege al resto de la población en edad jubilatoria. Así, la ley diferencia dos grupos: uno que ha realizado los aportes durante treinta años, y el otro, que no cumple esa condición. Luego fija una prestación que solo se otorga al primer grupo. El derecho a la seguridad social, consagrado en el Artículo 9 del PDESC y en el Artículo 14 bis de la Constitución argentina, está redactado con un alcance universal del modo ya explicado. Por lo tanto, la distinción necesita justificarse desde el punto de vista de su razonabilidad para que sea admisible. Corresponde revisar a) cuál es el objetivo legítimo que se busca al distinguir dos clases de jubilados; b) en qué medida esa división contribuye a lograrlo; y c) que no se imponga una limitación desproporcionada a los derechos de la clase que no recibe el beneficio. Si no se cumplen estas condiciones, la distinción es irrazonable y, por lo tanto, inconstitucional.

7 Recuperado de http://servicios.infoleg.gob.ar/infolegInternet/anexos/305000-309999/305214/norma.htm 
Corresponde ahora analizar el supuesto más frecuente con el que se intenta justificar políticas focalizadas, condicionadas o prioritarias. Se trata de la escasez presupuestaria. El argumento puede presentarse como reseña Dalli Almiñana $(2015$, p. 8): dado que no se cuenta con el dinero suficiente para brindar atención sanitaria a toda la población, se establece que solo se asistirá gratuitamente a un grupo que se halle en situación de necesidad grave (o extrema). No se trata de dar una atención adicional (una "acción positiva") a este colectivo, sino de limitar el alcance efectivo del derecho humano (a la salud, en este caso) a un sector definido, alegando la falta de presupuesto.

Quienes proponen este tipo de políticas suelen invocar una cláusula del PDESC como base. Se trata del Artículo 2.1, en el que los Estados se comprometen a lograr la vigencia de los derechos consagrados "hasta el máximo de los recursos de que disponga". Hay quienes leen en esas palabras una autorización para dejar de cumplir los derechos cuando el presupuesto se reduce. La focalización o la fijación de prioridades se presenta como una alternativa para decidir a quién garantizar los derechos (o algunos derechos) en el contexto de falta de recursos.

Esta interpretación no es acertada. El PDESC no autoriza la violación de derechos: simplemente toma en cuenta los factores materiales, inevitables en la reflexión jurídica. El Artículo 2.1 no permite establecer prioridades al distinguir entre personas de primera y de segunda o tercera clase. Por el contrario, esa cláusula señala un deber del Estado: utilizar todos los recursos para garantizar los derechos humanos.

No se refiere tan solo a lo que el Estado define como presupuesto sanitario, educativo o de vivienda. De lo contrario, existiría una vía sencilla para violar los derechos sin afrontar las consecuencias. Bastaría con que el Estado fijara cifras muy bajas para el gasto en educación, por ejemplo, para así poder destinar fondos a otros renglones, como el gasto militar o el pago a los acreedores externos.

Eso no está permitido por el Pacto porque, de lo contrario, el mismo tratado autorizaría su incumplimiento. Ello contradiría frontalmente el Artículo 26 de la Convención de Viena sobre el Derecho de los Tratados que consagra el principio pacta sunt servanda, esto es, el principio de la 
buena fe al momento de celebrar y ejecutar tratados (Diez de Velasco, 2005, p. 188).

El artículo en cuestión, por lo tanto, alude a los recursos del Estado considerados en conjunto: solo en una situación de escasez financiera general podría considerarse como solución excepcional la focalización en ciertos casos. El Comité de Derechos Económicos, Sociales y Culturales de Naciones Unidas, órgano de monitoreo del PDESC, ha aceptado tales alternativas pero solo como excepción: "todas las medidas de carácter deliberadamente retroactivo en este aspecto requerirán la consideración más cuidadosa y deberán justificarse plenamente por referencia a la totalidad de los derechos previstos en el Pacto y en el contexto del aprovechamiento pleno del máximo de los recursos de que se disponga" ${ }^{\prime}$. De modo que la simple invocación de falta de recursos o la excusa de proteger grupos o personas en situación de extrema vulnerabilidad no justifican la adopción de decisiones que recorten derechos. Se requiere una justificación profunda y completa de la inevitabilidad de tales medidas. No es suficiente alegar que se desea atender otros gastos (tales como la compra de armamentos o el pago de deuda externa) que no sirvan a la satisfacción directa de derechos humanos.

\section{Conclusiones}

En este punto puedo presentar una síntesis, una escala en la reflexión permanente sobre la relación entre políticas sociales y derechos sociales bajo el marco constitucional argentino.

En primer lugar, corresponde reconocer la formulación universal de los derechos sociales en el orden jurídico argentino, no solo desde 1994, sino también - en virtud del proyecto abierto a la inmigración- desde el texto constitucional sancionado en 1853: "todas las personas", "todos los habitantes" resultan titulares de los derechos consagrados.

8 Observación General 3 (1990), parágrafo 9. Una excepción al requisito del carácter deliberado de la medida regresiva se da en la Observación General 16 (2005), parágrafo 42. Allí se considera una violación del Pacto a las "medidas regresivas que afecten a la igualdad del derecho del hombre y la mujer en cuanto al disfrute de todos los derechos" contenidos en el tratado. 
La discusión más interesante, en cambio, se produce en torno a las políticas que se implementen para dar vigencia efectiva a los derechos sociales. Una primera lectura deja en pie solo a los modelos universalistas, de cobertura total e incondicionada, siguiendo el llamado "modelo Beveridge". Sin embargo, la lectura sistemática de la Constitución, incluyendo sus principios de federalismo ( $\mathrm{CN}$, Artículo 1), razonabilidad (Artículo 28) y grupos especialmente protegidos (CN, Artículo 75, incisos 17 y 23; CEDM; CDN; CDPD), además de las nociones de progresividad y la referencia a los recursos disponibles (PDESC, Artículo 2.2), hace admisibles políticas no universalistas en ciertos casos.

Resultan aceptables, entonces, la universalidad lograda a partir de la suma de programas establecidos por provincias o por sectores, siempre y cuando se alcance la cobertura total. Asimismo, es lícito crear programas especiales focalizados concebidos como "acción positiva" adicional a favor de ciertos grupos, siempre que ello no sustituya las políticas universales que deben mantenerse. También es admisible establecer ciertas condiciones para acceder a una política social, en tanto respeten el principio de razonabilidad y estén encaminadas, como reglamentación, a un fin legítimo sin que puedan afectarse la intimidad y la privacidad de las personas titulares de los derechos. Finalmente, en casos de escasez presupuestaria general, es posible aceptar políticas regresivas si se cumplen las condiciones fijadas por el Comité DESC (esto es, una justificación plena de la medida, con referencia a todos los derechos humanos).

El carácter imperativo y supremo de la universalidad hace posible -como señalamos en la introducción - un control de constitucionalidad de las políticas públicas. Entendido en un sentido muy amplio, puede llevarse por diversas vías mediante la acción política general o ante las instituciones. Es posible plantear argumentos constitucionales en la esfera pública o a través de presentaciones ante las instancias administrativas o legislativas competentes. En el ámbito judicial, se realiza el control de constitucionalidad en sentido estricto. Puede llevarse a cabo por medio de la ya descrita acción de amparo. Cada norma que se dicta para implementar una política, o cada acción u omisión de autoridades o particulares, puede someterse a control de constitucionalidad si se ha afectado en forma "actual o inminente" un derecho (CN, Artículo 43). Los ejemplos de la AUH o de la pensión establecida por la llamada "Reforma Previsional" 
sirven para imaginar cómo podría ponerse en marcha ese proceso. Quien se haya visto impedido de acceder a la AUH o de recibir el 82 \% móvil de su ingreso como activo, podrá impugnar como inconstitucionales las normas que establecen ese recorte excluyente, invocando la violación del principio de universalidad (y el de igualdad, posiblemente). Incluso podría ser planteado a través de una acción colectiva impulsada por las asociaciones previstas en el Artículo 43 de la CN.

Como se ve, las reflexiones aquí desarrolladas permiten rechazar -desde un punto de vista de derechos humanos- los argumentos por lo general empleados desde los organismos políticos para justificar diversas modalidades no universales de política social. A la vez, permiten replantear, bajo ese mismo punto de vista, nuevas modalidades para diseñar políticas factibles orientadas a lograr la vigencia progresiva, plena y efectiva de los derechos sociales con el fin de evitar su impugnación constitucional.

\section{Referencias}

Abramovich, V. y Courtis, C. (2002). Los derechos sociales como derechos exigibles. Madrid: Trotta.

Antoni, N. (1950). Los derechos sociales en la Constitución Nacional argentina de 1949. En A. Valle, Subordinación y contrato de trabajo, pp. 24-51. Buenos Aires: s. d.

Banco Mundial (2015). Going universal. How 24 developing countries are implementing Universal Health Coverage reforms from the bottom up. Washington, D. C.: Banco Mundial. Recuperado de http://documents.worldbank.org/ curated/en/2015/09/25018544/going-universal-24-developing-countriesimplementing-universal-health-coverage-reforms-bottom-up

Bestard, A. M., Carrasco, M. y Pautassi, L. (2015). La cuestión federal pendiente: sistemas previsionales locales y brechas contributivas. En L. Pautassi y G. Gamallo (coords.), El bienestar en brechas. Las politicas sociales en la Argentina de la posconvertibilidad, pp. 91-133. Buenos Aires: Biblos.

Bidart Campos, G. J. (1991). Teoría general de los derechos humanos. Buenos Aires: Astrea.

Bidart Campos, G. J. (2000). Tratado elemental del derecho constitucional argentino. Tomo I-A. Buenos Aires: Ediar. 
Clerico, L., Ronconi, L. y Aldao, M. (eds.). (2013). Tratado del derecho a la salud. Tomo I. Buenos Aires: La Ley.

Courtis, C. (2006). La prohibición de regresividad en materia de derechos sociales: apuntes introductorios. En C. Courtis (comp.), Ni un paso atrás. La prohibición de regresividad en materia de derechos sociales, pp. 3-52. Buenos Aires: Editorial Del Puerto.

Dalla Via, A. (2004). Manual de derecho constitucional. Buenos Aires: LexisNexis.

Dalli Almiñana, M. (2015). Universalidad del derecho a la salud e igualdad material. Desigualdades económicas y sociales y desigualdades en salud. Universitas. Revista de Filosofí, Derecho y Política, (22), 3-31. Recuperado de https://e-revistas.uc3m.es/index.php/UNIV/article/view/2685

Dalli Almiñana, M. (2017). La titularidad universal del derecho a la salud: algunos límites en su implementación. Tesis doctoral. Programa de Doctorado en Derechos Humanos, Democracia y Justicia internacional (Universitat de València). Recuperado de http://roderic.uv.es/handle/10550/58400

Díez de Velasco, M. (2005). Instituciones de Derecho Internacional. Madrid: Tecnos. Esping-Andersen, G. (1993). Los tres mundos del Estado de Bienestar. Valencia: Alfons el Magnànim.

Filgueira, F. (2014). Hacia un modelo de protección social universal en América Latina. Santiago de Chile: CEPAL.

Fiszbein, A. et al. (2009). Panorama general. Transferencias monetarias condicionadas. Reduciendo la pobreza actual y futura. Washington D.C.: Banco Mundial. Recuperado de http://siteresources.worldbank.org/INTCCT/Resources/5757608-1234228266004/CCTS-Overview-Spanish.pdf.

Gelli, M. A. (2005) Constitución de la Nación Argentina. Comentada y concordada. Buenos Aires: La Ley.

Hernández, A. M. (2009). Federalismo y constitucionalismo provincial. Buenos Aires: Abeledo Perrot.

Jiménez, E. P. (2015). El derecho de toda persona a interponer acción expedita y rápida en defensa de sus derechos constitucionales. Análisis del Artículo 43 de la Constitución Nacional. En M.Bernal, C. Pizzolo y A. Rossetti (coords.), iQue veinte años no es nada! Un análisis crítico a veinte años de la reforma constitucional de 1994 en Argentina, pp. 327-353. Buenos Aires: Eudeba.

Lema Añón, C. (2009). Salud, Justicia, Derechos. El derecho a la salud como derecho social. Madrid: Dykinson.

Lema Añón, C. (2010). Derechos sociales, ¿para quién? Sobre la universalidad de los derechos sociales. Derechos y Libertades, (22), 179-203. 
Lema Añón, C. (2011). Universalidad de los derechos humanos. Diccionario Iberoamericano de Derechos Humanos y Fundamentales. Recuperado de http:// diccionario.pradpi.org/inicio/index.php/terminos_pub/view/129

Lema Añón, C. (2012). Apogeo y crisis de la ciudadanía de la salud. Cuadernos Bartolomé de las Casas 53. Madrid: Dykinson.

Lessa Kerstenetzky, C. (2006). Políticas sociais: focalização ou universalização? Revista de Economía Política, 26(104), 564-574.

Leubolt, B., Fischer, K. y Saha, D. (2014). Are targeting and universalism complementary or competing paradigms in social policy? Insights from Brazil, India and South Africa. International Journal of Labour Research, 6(1), 75-93. Manili, P. (2002). La supremacía constitucional en relación al derecho internacional y a los instrumentos internacionales de derechos humanos con jerarquía constitucional. En D. Sabsay (coord.). Colección de análisis jurisprudencial. Derecho constitucional, pp. 79-87. Buenos Aires: La Ley.

Nino, C. S. (1992). Fundamentos de derecho constitucional. Análisis filosófico, jurídico y politológico de la práctica constitucional. Buenos Aires: Astrea.

Oszlak, O. (2009). Implementación participativa de políticas públicas. Aportes a la construcción de un marco analítico. En A. Belmonte et al., Construyendo confianza. Hacia un nuevo vínculo entre Estado y Sociedad Civil. Buenos Aires: CIPPEC y Subsecretaría para la Reforma Institucional y Fortalecimiento de la Democracia, Jefatura de Gabinete de Ministros, Presidencia de la Nación. Recuperado de http://www.oscaroszlak.org.ar/images/articulos-espanol/ Implem\%20parti\%20de\%20pol\%20publicas.pdf

Peña Freire, A. M. (2016). La teoría fuerte de los derechos sociales: reconstrucción y crítica. Cuadernos Electrónicos de Filosofía del Derecho, (34), 251-269. Recuperado de https://ojs.uv.es/index.php/CEFD/article/view/8262/8811 Quiroga Lavié, H. (2000). Constitución de la Nación argentina. Comentada. Buenos Aires: Zavalía.

Rivera, J. C., Grosman, L. S., y Legarre, S. (eds.). (2014). Tratado de los Derechos Constitucionales. Tomo I. Buenos Aires: Abeledo Perrot.

Rosatti, H. (2010). Tratado de derecho constitucional. Santa Fe: Rubinzal Culzoni. Rossetti, A. y Álvarez, M. (coords.) (2010). Derecho a la igualdad. Un análisis desde el método de casos. Buenos Aires: Advocatus-CIIS.

Sagüés, N. P. (1999). Elementos de derecho constitucional (2 tomos). Buenos Aires:. Astrea.

Sepúlveda, M. (2006). La interpretación del Comité de Derechos Económicos, Sociales y Culturales de la expresión "progresivamente". En C. Courtis 
(comp.), Ni un paso atrás. La prohibición de regresividad en materia de derechos sociales, pp. 117-150. Buenos Aires: Editorial Del Puerto.

Sepúlveda, M. (2014). De la retórica a la práctica: el enfoque de derechos en la protección social en América Latina. Santiago de Chile: CEPAL.

Skocpol, T. (1991). Universal appeal: Politically viable policies to combat poverty. The Brookings Review, (9), 29-33.

Straschnoy, M. (2016). Usos y razones de las condicionalidades en la política social argentina. En L. Pautassi y G. Gamallo (coords.), El bienestar en brechas. Las politicas sociales en la Argentina de la posconvertibilidad, pp. 167-198. Buenos Aires: Biblos.

Sola, J. V. (2004). Manual de derecho constitucional. Buenos Aires: LexisNexis.

Sunstein, C. (2004). The second bill of rights: FDR's unfinished revolution and why we need it more than ever. Nueva York: Basic Books.

Young, K. G. (2014). Constituting economic and social rights. Oxford: Oxford University Press. 